Editorial

\title{
Revista Urología Colombiana RUC: 35 de años evolución, cambio e impacto.
}

\author{
Andrés Felipe Gutiérrez Rojas ${ }^{10}$ \\ ${ }^{1}$ Hospital Universitario San Ignacio
}

Urol Colomb 2021;30(4):e223-e224.

"Con la entrega del primer número de la Revista Urología Colombiana, se cumple un anhelo de sus miembros y una necesidad científica de nuestro país, para llenar un vacío en la bibliografía médica nacional".

Con esta frase del profesor José Armando López se marcó un hito en la urología del país, la primera edición de Revista Urología Colombiana (RUC) en julio de 1986, y que desde entonces ha permanecido continuamente publicada por 35 años.

La Revista Urología Colombiana materializa un objetivo de la Sociedad Colombiana de Urología (SCU) como medio de difusión científico oficial de los resultados de investigación original, y de otro tipo trabajos de diferente diseño metodológico, con el único propósito de contribuir al incremento del conocimiento médico en el campo de nuestra especialidad. Tardaría casi 30 años desde la fundación de la SCU para lograr la aparición de RUC, que precedida por publicaciones efímeras como el "Boletín de Actividades" o el resumen del congreso. ${ }^{1}$

En los 30 volúmenes publicados hasta hoy, se puede ver claramente reflejado el aporte de cada uno de los editores y colaboradores en mantener el más estricto cumplimiento del proceso editorial, un incremento progresivo en la calidad de su contenido y su validez o aplicabilidad en el medio nacional, regional o mundial, en virtud de lo cual ha sido posible que RUC se encuentre indexada en bases referencia y citación bibliográfica científica de amplio reconocimiento como Scopus, SCImago Journal Rank SJR, Directory of Open Access Journals DOAJ, Literatura Latinoamericana y del Caribe en Ciencias de la Salud (LILACS), Red de Revistas Científicas de América Latina y el Caribe, España y Portugal (Redalyc), Dialnet y a nivel Colombia, en Publindex.

Ha sido y será una política la de mantenernos como una fuente de consulta libre, por fuera de las limitaciones al acceso del conocimiento económicas u de otra índole, así como una publicación libre cobro o cargos a los autores garantizando un serio proceso de revisión por pares y de rigurosidad científica, que nos ha valido ser referenciados en la Urology Green List como una revista segura, transparente y no depredadora.

No hemos sido ajenos a los avances y los retos que nos plantea la comunidad científica, la tecnología y la sociedad. RUC ha migrado del tradicional formato de publicación impresa periódica local en español a una publicación digital bilingüe con divulgación global, lo cual ha permitido que con mayor frecuencia sean sometidos trabajos procedentes de otros países y en inglés, así como su lectura más allá de nuestras fronteras.

Que RUC sea reconocida como una ventana de oportunidad y medio de propagación del conocimiento urológico, es, sin duda, un desafío a corto plazo frente al incremento de revistas registradas en las bases de citación, ejemplo de ello es el histórico del indicador SCImago Journal Rank, en donde en 1999 se incluían 68 revistas y para 2020 fueron $107 .^{2}$ Sin lugar a duda, el aspecto más relevante para los autores al momento de someter sus trabajos, además de la creciente disponibilidad de revistas, es el factor de impacto. Definitivamente RUC no es la misma que hace 35 años. El perfil del contenido ha evolucionado, pasando principalmente de reportes de caso y revisiones a una revista que presenta trabajos con diseños metodológicos de mayor rigor e impacto de tipo analítico, experimentales y de síntesis de evidencia, ${ }^{3}$ posicionándonos como una opción cada vez más atractiva y con un incremento progresivo de la factor de impacto, sin embargo, esto requiere de una intensa colaboración por parte de la comunidad científica en confiar sus trabajos a nosotros, de los integrantes de los procesos editoriales y de la referenciación de trabajos publicados en RUC.

Nuestra revista ha sido y es "escuela" para aquellos entusiastas de la urología, especialmente en Colombia, formando y estimulando la estructuración del proceso de
Address for correspondence Andrés Felipe Gutiérrez Rojas, (e-mail: afgutierrez@husi.org.co).
DOI https://doi.org/ 10.1055/s-0041-1740544. ISSN 0120-789X. e ISSN 2027-0119.
(C) 2021. Sociedad Colombiana de Urología. All rights reserved. This is an open access article published by Thieme under the terms of the Creative Commons Attribution-NonDerivative-NonCommercial-License, permitting copying and reproduction so long as the original work is given appropriate credit. Contents may not be used for commercial purposes, or adapted, remixed, transformed or built upon. (https://creativecommons.org/ licenses/by-nc-nd/4.0/)

Thieme Revinter Publicações Ltda., Rua do Matoso 170, Rio de Janeiro, RJ, CEP 20270-135, Brazil 
investigación para lograr un producto con valor y aplicación en diferentes escenarios de práctica.

Urología Colombiana no solo llegó a ocupar un puesto en el vacío de las publicaciones médicas en el país o la región, es un espacio dedicado a contribuir al cuidado de los pacientes ajustado a las posibilidades, éxitos o fracasos, resultado de la ciencia y la investigación en nuestra especialidad.

Dedicamos algunas páginas de esta edición como homenaje y reconocimiento al esfuerzo de los editores anteriores, los pares de revisión y a todos aquellos que han contribuido a mantener vigente a RUC hoy y proyectarla hacia el futuro.
Conflictos de Interés

El autor no declara conflictos de interés.

\section{Referencias}

1 Acuña A. (2007). Capítulo IV. Estructura y Desarrollo de la Sociedad Colombiana de Urología. Revista “Urología Colombiana”. Historia de la Urología en Colombia (pp.108-111). ALTA VOZ Comunicaciones.

2 Scimago Lab. Journal rankings on Urology. Recuperado 1 Noviembre, 2021, de. https://www.scimagojr.com/journalrank. php? category $=2748$ \&year $=2020$

3 García-Perdomo HA. Editorial: Del reporte de caso a otros diseños. Urol Colomb 2019;28:3-4. Doi: 10.1055/s-0039-1677860. https://www. thieme-connect.com/products/ejournals/pdf/10.1055/s-0039-1677860. pdf 